\title{
Edukasi Kanker Serviks dan Pemeriksaan PAP Smear Pada Ibu-lbu Di RW 04 Mojosongo Surakarta
}

\begin{tabular}{|c|c|c|}
\hline \multicolumn{3}{|c|}{$\begin{array}{c}\text { Gunawan Pamudji Widodo, Yane Dila Keswara,NurAiniDewi, Supriyadi } \\
\text { Universitas Setia Budi } \\
\text { E-mail: gunawanpamudji@yahoo.com }\end{array}$} \\
\hline Info Artikel & & Abstract \\
\hline \multirow[b]{3}{*}{$\begin{array}{l}\text { Kata kunci: } \\
\text { Pendidikan, } \\
\text { Serviks dan } \\
\text { PAP Smear }\end{array}$} & & $\begin{array}{l}\text { The quality of public health needs to be improved through pap } \\
\text { smear education and examination. This service activity was } \\
\text { motivated by a lack of knowledge of cervical cancer and the } \\
\text { willingness of residents to do pap smear examinations. The } \\
\text { purpose of this service is to increase knowledge of cervical } \\
\text { cancer, how to early detection and conduct pap smear } \\
\text { examinations. This service is carried out in the form of education } \\
\text { about cervical cancer and pap smear examination, reading of } \\
\text { result and recommendation for prevent of cervical cancer. This } \\
\text { service was carried out for } 2 \text { meetings, which were attended by } 20 \\
\text { womenin RW 04, Mojosongo, Surakarta. The results of this } \\
\text { service can increase the knowledge about cervical cancer and its } \\
\text { detection. The results of pap smear tests from } 20 \text { women were } \\
\text { declared negative for cervical cancer. }\end{array}$ \\
\hline & & Abstrak \\
\hline & $\begin{array}{l}\text { Kanker } \\
\text { Deteksi }\end{array}$ & $\begin{array}{l}\text { Kualitas kesehatan masyarakat perlu ditingkatkan melalui } \\
\text { pendidikan dan pemeriksaan pap smear. Kegiatan layanan ini } \\
\text { dimotivasi oleh kurangnya pengetahuan tentang kanker serviks } \\
\text { dan keinginan warga untuk melakukan pemeriksaan pap smear. } \\
\text { Tujuan dari layanan ini adalah untuk menambah pengetahuan } \\
\text { tentang kanker serviks, cara deteksi dini dan melakukan } \\
\text { pemeriksaan pap smear. Layanan ini dilakukan dalam bentuk } \\
\text { edukasi tentang kanker serviks dan pemeriksaan pap smear, } \\
\text { membaca hasil dan rekomendasi untuk pencegahan kanker } \\
\text { serviks. Layanan ini dilakukan untuk } 2 \text { pertemuan, yang dihadiri } \\
\text { oleh } 20 \text { wanita di RW 04, Mojosongo, Surakarta. Hasil dari } \\
\text { layanan ini dapat meningkatkan pengetahuan tentang kanker } \\
\text { serviks dan pendeteksiannya. Hasil tes pap smear dari } 20 \text { wanita } \\
\text { dinyatakan negatif untuk kanker serviks. }\end{array}$ \\
\hline
\end{tabular}

\section{PENDAHULUAN}

Tiap tahun terjadi sekitar 21.000 kasus kanker serviks (leher rahim) di Indonesia sehingga menempati nomor dua dalam jumlah tertinggi di dunia. Pada 2014, lebih dari 92 ribu perempuan Indonesia meninggal karena kanker dengan 10,3 persen di antaranya akibat kanker serviks. Salah satu pendorong tingginya angka tersebut karena tidak adanya proses pemantauan sejak dini. Sebagian besar penderita kanker serviks baru menyadari saat kondisinya sudah parah. Setiap tahun biaya untuk penanganan kanker serviks mencapai Rp7,2 triliun. Tidak semua penderita yang sudah mendapatkan pengobatan bisa diselamatkan, karena sudah mengalami stadium berat. Di sisi lain, penderita kanker serviks juga produktivitasnya berkurang. Deteksi dini melalui tes IVA (tes inspeksi visual dengan asam asetat)ataumelalui pap smear akan menyelamatkan nyawa, meningkatkan produktivitas dan menekan pengeluaran biaya terapi (Vetriciawizach, 2017).

Pap smear adalah tes skrining untuk kanker serviks atau kanker mulut rahim. Sel yang didapatkan dari apusan serviks pada pemeriksaan pap smear kemudian 
diperiksa di bawah mikroskop. Setiap wanita yang sudah berhubungan seksual wajib melakukan pemeriksaan pap smear. Tujuannya untuk melihat perkembangan di selsel serviks terutama pada wanita yang sudah melakukan hubungan seks. Pap smear dapat menunjukkan adanya perubahan pada area serviks setahun setelah hubungan seks pertama kali. Kadang perubahan akan berjalan seiring dengan waktu dan intensitas hubungan seks yang dilakukan sehingga diperlukan pemeriksaan yang sifatnya rutin, 1 tahun sekali atau 6 bulan sekali (terutama pada individu yang diduga beresiko tinggi, terama tiadanya peradangan pada area serviksdenganjenisperadangankelastertentu). Ketika perubahan tersebut teramati lebih dini maka penanganan akan bias menangkal perkembangan kearahkankerserviks, kemungkinan penyembuhan juga lebih bias diharapkan (Kustiyati, 2007).

Beberapa kendala dalam pemeriksaan dini kanker serviks terkait masalah biaya, ketidaktahuan, perasaan malu atau takut sehingga membuat para ibu enggan melakukannya. Rasa malu terutama karena harus melakukan pemeriksaan bagian intim dari organ seks wanita. Beberapa keterangan menyebutkan ada kekhawatiran bahwa akan diketahui aktivitas seks dari wanita yang belum menikah walaupun sudah masuk usia produktif (Safutra, 2017). Denganadanyakegiatanini, maka diharapkan para ibu atau wanita yang sudah memasuki usia produktif dapat lebih memahami pentingnya pemeriksaan dini terkait kesehatan serviksnya melalui pemeriksaan pap smear, lebih terbuka untuk menyampaikan keluhan terkait gangguan organ seks khususnya serviks, sehingga penyampaian informasi dari tim PkM dan petugas medis dapat lebih terarah, sesuai dengan masalah yang terjadi pada tiap individu.

Sasaran dalam kegiatan pengabdian kepada masyarakat ini adalah ibu-ibu di wilayah RW 04 Mojosongo Surakarta. Kegiatan ini diharapkan dapat membantu masyarakat, terutama kaum ibu, untuk lebih memahami kesehatan organ seks mereka, mengetahui cara perawatan yang baik terhadap organ vital, dan mewaspadai bilamana terjadi perubahan area serviks yang mengarah ke keganasan (kanker serviks) sehingga bisa mencegah kemungkinan terjadi kanker lebih dini atau menangani kanker serviks lebih dini.

\section{METODE PENELITIAN}

Penyuluhan tentang kanker serviks dan beberapa metode pemeriksaan dini terhadap kanker serviks yang diikuti dengan pemeriksaan melalui pap smear pada ibu-ibu di wilayah RW 04 akan menjadi solusi bagi kurangnya pengetahuan para kaum ibu terhadap kesehatan area serviks. Melalui penyuluhan ini diharapkan akan menyadarkan pentingnya melakukan perawatan kesehatan area serviks dan pemeriksaan dini terhadap kemungkinan adanya perubahan area serviks melalui pap smear. Dengan menumbuhkan kesadaran pada kaum ibu diharapkan nantinya dapat menekan angka kejadian kanker serviks terutama di wilayah Mojosongo Surakarta pada umumnya. Secara detail, masalah dan solusi yang ditawarkan untuk mitra tersaji dalam tabel 1sebagai berikut:

Tabel1. Masalah dan Solusi yang ditawarkan pada Mitra

\section{Masalah}

Ibu-ibudi RW 04 kurang mengetahui tentangupayapemeliharaan

sekskhususnyaserviksdan

Solusi yang ditawarkan

Pemberianpenyuluhanmengenaipemeriksaandiniterhadapka nkerserviks. 
metodepemeriksaandiniterhadapkanke

rserviks

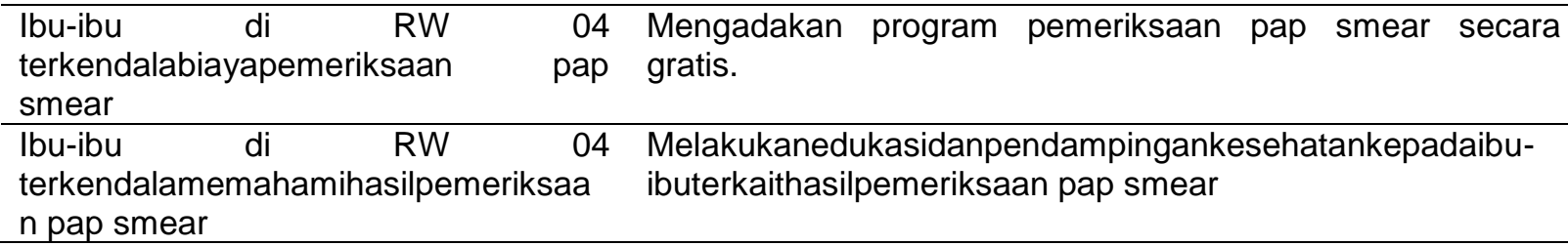

\section{PEMBAHASAN}

\section{Pemberianpenyuluhanmengenaipemeriksaandiniterhadapkankerserviks}

KegiatanpenyuluhandilakukanpadahariMinggu, 19 Agustus 2018.

Penyuluhanbertujuanuntukmeningkatkanpengetahuanbagiibu-ibuRw

terkaitkankerservikssertacaramencegahdanmendeteksinya.

lbu-

ibudikenalkantentangserviksdankankerserviksmelaluipresentasigambar. Selainitu, jugadiberikanedukasiterkaitpencegahandinikankerserviksdancaramendeteksikankers erviksmelaluipresentasidanpembagian leaflet.

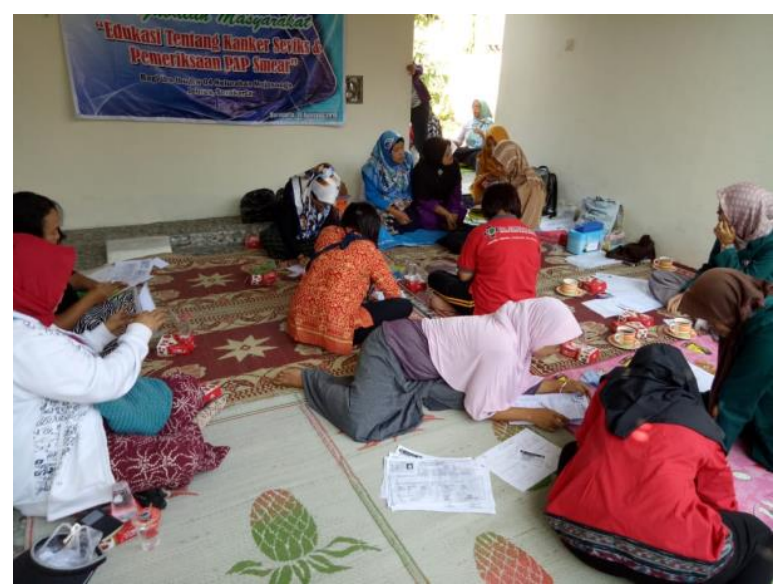

Gambar 1. Kegiatanpenyuluhankankerserviks

\section{Programpemeriksaan pap smear.}

PemeriksaandilakukanpadahariMinggu, setelahpenyampaianpenyuluhan. ibutelahdidatadandisampaikanpersyaratanuntukbisadilakukanpemeriksaanpaps smear. salahsaturumahwargadandilaksanakandenganbantuan tenaga medis/perawat dari laboratorium klinik RahanuKaranganyar. Persiapan yang harusdilaksanakansebelumpemeriksaanyaitu minggusebelummenstruasiatau 1 minimal tidakmelakukanhubungansuamiistri minimal 2 harisebelumpemeriksaan, dantidakmenggunakan tampon vagina/ pembilas vagina/ obat-obatan yang dimasukkanmelalui vagina.

Dari 30 orang yang terdatahanya 20 orang yang memenuhipersiapanpemeriksaan. Satupersatupesertadidatadandiperiksa. Dari 20 pesertainiada yang sudahpernahmelakukanpemeriksaan pap smear sebelumnya, 
danadajuga yang barupertama kali pemeriksaan. Para ibu-ibupesertaada yang sangatantusiasuntukdapatmelakukanpemeriksaan, adajuga yang merasatakutsertamaluuntukdiperiksatetapijugapenasaranterhadaphasilnya. Hasilpemeriksaandapatdiperolehsekitar 1-2 minggukemudian.

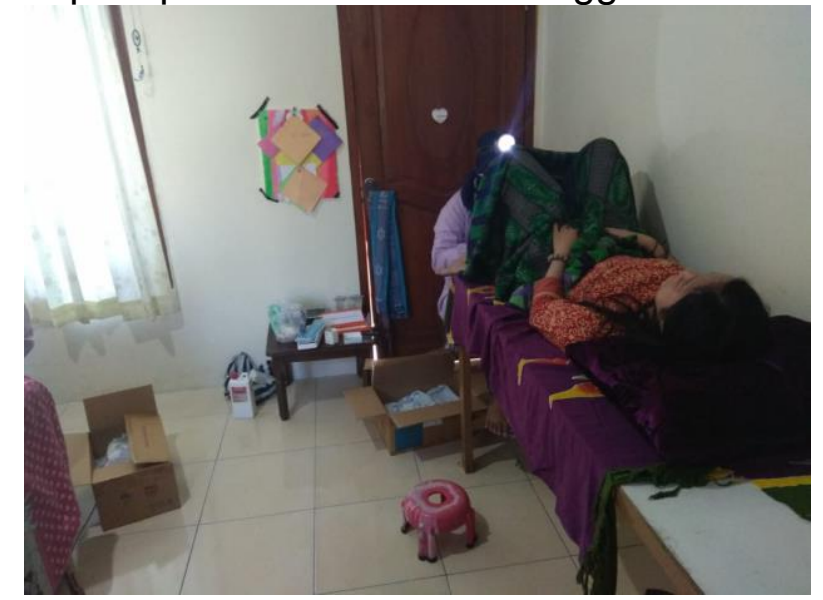

Gambar 2. Kegiatanpemeriksaan pap smear

\section{Penyampaianhasilpemeriksaandanedukasiterkaithasilpemeriksaan} smear

PembagiandanedukasihasilpemeriksaandilakukanpadahariKamis, $\quad 20$ September $2018 \quad$ di rumahsalahsatuwarga. Ibuibusangatantusiasdanpenasaranterhadaphasilpemeriksaan pap smear. Hasil di bagisatupersatukeibu-ibukemudiansetelahmendapatkanhasilsetiapwarga di beripenjelasantentanghasillaboratorium yang diperoleh. Masingmasingwargaaktifbertanyaterhadaphasil yang diperoleh.

Dari 20 pesertapemeriksaan pap smear didapatkanhasil 9 pesertadenganhasil Normal smear klas I dimanadirekomendasikanuntukkontrolpemeriksaan pap smear 1 tahunlagi, 3 pesertadenganhasil Normal Atrophic Smear klas I dimanadirekomendasikanuntukkontrolpemeriksaanpapsmear $\quad \begin{array}{lll}1 & \text { tahunlagi, } 5\end{array}$ pesertadenganhasilRadangtidakkhasklas dimanadirekomendasikanuntukkonsultasidengandokterkarenaadaperadangansetelah itubarupemeriksaanpapsmearkembali, 1 pesertadenganhasilRadangtidakkhasklas II dimanadirekomendasikanuntukkontrolpapsmear 6 bulanlagi, $\quad$ dan 2 pesertadenganhasilRadangtidakkhaspada atrophic smear klas I direkomdasikanuntuksegerakonsultasidengandokterkarenaadaperadangansetelahitu barupemeriksaan pap smear kembali. 


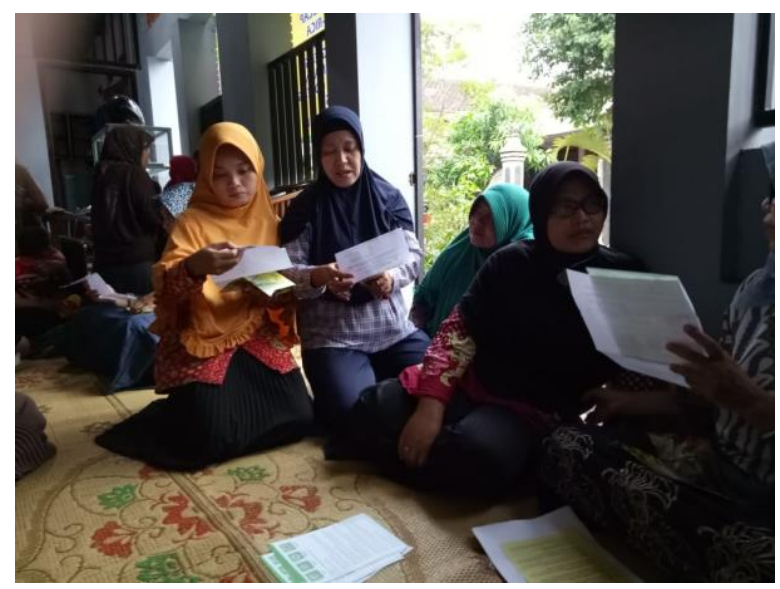

Gambar 3. Kegiatanpenyampaianhasilpemeriksaan pap smear danedukasipadaibuibu RW 04

Hasil pap smear beberapa peserta menunjukkan hasil abnormal, hal ini bisa disebabkan oleh banyak faktor. Sehingga tidak selalu berarti peserta sedang mengidap kanker. Hasil abnormal peserta ditemukan adanya peradangan. Peradangan dari peserta diakibatkan oleh banyak faktor. Seperti karena adanya keputihan, ada perubahan hormon, dan bisa juga karena ada infeksi bakteri, parasite atau jamur. Beberapa sel abnormal serviks dapat berkembang menjadi kanker. Sehingga bila diketemukan adanya sel-sel abnormal pra kanker, jangan menunda pengobatan. Segera berkonsultasi dengan dokter kandungan untuk penanganan selanjutnya.

4. Evaluasi

Tahap ini bertujuan untuk mengevaluasi hasil kegiatan yang sudah dilakukan pada tahap sebelumnya. Kegiatan tahap evaluasi yaitu menanyakan kepada ibu-ibu apakah mereka sudahpahampentingnyamenjagakebersihanserviks, caramencegahkankerservik, danbagaimanacaradeteksidini.

\section{PENUTUP}

Edukasitehadapkankerserviksdanpemeriksaan pap smear padaibu-ibu RW 4, Mojosongomerupakan salah satu programuntukmeningkatkankualitaskehidupanmasyarakatkhususnyadibidangkesehat an. dapatmembantumeningkatkankesadaranibu-

Setelahpelaksanaankegiataninidiharapkan ibuakanpentingyamenjagakebersihanserviksdanrutinpemeriksaan pap smear setahunsekaligunamedeteksiadanyakankerserviks.

\section{REFERENCES}

Vetriciawizach, 2017, JumlahKasusKankerServiks Indonesia Tertinggi ke-2 di Dunia, CNN Indonesia, diakses 20 September 2018, https://www.cnnindonesia.com/gaya-hidup/20170827161551-255237610/jumlah-kasus-kanker-serviks-indonesia-tertinggi-ke-2-di-dunia. 
Kustiyati, S., 2007, "Pap Smear", GASTER, Volume 3 Nomor 2, hal 115-123.

Safutra, I., 2017, TerungkapAlasanPerempuanEngganLakukan Pap Smear, Jawapos, diaksestanggal $20 \quad$ Agustus 2018, https://www.jawapos.com/kesehatan/womens/15/06/2017/terungkap-alasanperempuan-enggan-lakukan-pap-smear 